\title{
Antibiotic prescribing for discoloured sputum in acute cough/lower respiratory tract infection
}

\author{
C.C. Butler, M.J. Kelly, K. Hood, T. Schaberg, H. Melbye, M. Serra-Prat, F. Blasi, \\ P. Little, T. Verheij, S. Mölstad, M. Godycki-Cwirko, P. Edwards, J. Almirall, \\ A. Torres, U-M. Rautakorpi, J. Nuttall, H. Goossens and S. Coenen
}

ABSTRACT: We investigated whether discoloured sputum and feeling unwell were associated with antibiotic prescription and benefit from antibiotic treatment for acute cough/lower respiratory tract infection (LTRI) in a prospective study of 3,402 adults in 13 countries.

A two-level model investigated the association between producing discoloured sputum or feeling generally unwell and an antibiotic prescription. A three-level model investigated the association between an antibiotic prescription and symptom resolution.

Patients producing discoloured sputum were prescribed antibiotics more frequently than those not producing sputum (OR $3.2,95 \% \mathrm{Cl} 2.1-5.0$ ), unlike those producing clear/white sputum (OR $0.95,95 \% \mathrm{Cl} 0.61-1.48)$. Antibiotic prescription was not associated with a greater rate or magnitude of symptom score resolution (as measured by a 13-item questionnaire completed by patients each day) among those who: produced yellow (coefficient $0.00 ; p=0.68$ ) or green (coefficient $-0.01 ; p=0.11$ ) sputum; reported any of three categories of feeling unwell; or produced discoloured sputum and felt generally unwell (coefficient $-0.01 ; p=0.19$ ).

Adults with acute cough/LRTI presenting in primary care settings with discoloured sputum were prescribed antibiotics more often compared to those not producing sputum. Sputum colour, alone or together with feeling generally unwell, was not associated with recovery or benefit from antibiotic treatment.

KEYWORDS: Acute cough, antibiotic resistance, antibiotic treatment, lower respiratory tract infection, primary care sputum

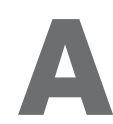

cute cough is one of the most common reasons for consulting and for prescribing antibiotics in primary care [1-3]. Feasible clinical strategies are needed for more effective targeting of antibiotic treatment to those who will receive meaningful benefit in order to contain antimicrobial resistance, reduce cost, promote self-care and reduce unnecessary risk from sideeffects [4, 5]. Physicians commonly ask their patients about the colour of their sputum and how unwell they are feeling to inform their decision of whether or not to prescribe an antibiotic for acute cough, based on the assumption that purulence is more likely to reflect a bacterial cause and predict improved outcomes from antibiotics [6-8]. Clinicians regard patients who feel both systemically unwell and who also produce discoloured sputum an even higher priority for an antibiotic prescription [9-11]. Guidelines identify purulent sputum as one of a cluster of clinical features that should alert clinicians to possible serious lung infection [12]. Patients are also more likely to associate purulence with the need for antibiotic treatment $[13,14]$.

However, it is not clear which symptoms and clinical signs predict improved outcomes from antibiotic treatment, and the usefulness of sputum colour in predicting benefit from antibiotic treatment among patients with acute cough is controversial $[15,16]$. Increasing diagnostic uncertainty is associated with increased unnecessary antibiotic prescription [17]. Therefore, using data from our large, prospective, observational
AFFILIATIONS

For a full list of affiliations see the Acknowledgements section.

\section{CORRESPONDENCE}

C.C. Butler

Primary Care and Public Health Cardiff University

3rd floor

Neaudd Meirionnydd

Cardiff

CF14 4YS

UK

E-mail: butlercc@Cardiff.ac.uk

Received:

Aug 202010

Accepted after revision:

Jan 092011

First published online:

March 152011 
study of the presentation, management and outcome of acute cough [3], we explored whether adult patients presenting to a general practice with acute cough who produced discoloured sputum and/or were feeling generally unwell were more likely to be prescribed antibiotics. We also examined whether symptom score resolution differed between these patients and those who did not produce discoloured sputum and/or were feeling generally unwell, and whether this was associated with antibiotic treatment.

\section{MATERIALS AND METHODS Study subjects}

Eligible patients were aged $\geqslant 18$ yrs and were presenting with an illness where an acute or worsened cough was the main or dominant symptom, or had a clinical presentation that suggested a lower respiratory tract infection (LRTI), with a duration of $\leqslant 28$ days. We asked clinicians to attempt to enrol consecutive eligible patients from October to November 2006 and late January to March 2007. However, the networks were not able to ask clinicians to complete a log of all eligible patients. Ethical approval was obtained in each network.

\section{Study design}

This was a further analysis from a prospective observational study in 14 primary care networks in 13 European countries with clinicians recording symptoms on presentation and management. More details on this observational GRACE (Genomics to Combat Resistance Against Antibiotics in Community-Acquired LRTI in Europe; www.grace-lrti.org) study of acute cough have been reported elsewhere [3]. The objectives of the study were to investigate whether discoloured sputum and feeling unwell were associated with antibiotic prescription and predicted benefit from antibiotic treatment for acute cough. The study sample size was based on an estimate of a probability of $50 \%$ for certain events, such as treatment decisions $(50 \%$ is the most conservative estimate of probabilities in statistical terms; more common or more rare events would give more power). This required a total sample size of 270 patients per network to give a 95\% confidence interval of $44-56 \%$ for detecting that $50 \%$ probability within each network. This study uses all available data. The study was not, therefore, specifically powered for this analysis: we used all available data and provide confidence intervals for interpretation of the precision of our estimates.

\section{Methods}

Clinicians recorded aspects of patients' history, symptoms, comorbidities (diabetes, chronic lung disease including chronic obstructive pulmonary disease (COPD), cardiovascular disease and presence of asthma), clinical findings and management, including antibiotic prescription on a case report form (CRF). One of the symptoms that clinicians recorded was whether patients felt generally unwell. Clinicians rated whether this symptom constituted "no problem", a "mild problem", a "moderate problem" or a "severe problem" for the patient. Clinicians indicated the presence or absence of 13 other symptoms in the same way (cough, sputum production, shortness of breath, wheeze, coryza, fever during this illness, chest pain, muscle aching, headache, disturbed sleep, interference with normal activities, confusion/disorientation and diarrhoea). They were also asked to record the colour of the patient's sputum (if present) as clear, white, yellow or green. Clear or white sputum was denoted normal, and yellow and green sputum was denoted discoloured. Clinicians were not routinely asked to check the patients' sputum colour themselves, as we wanted data to best represent everyday practice. Clinicians recorded their management, including antibiotic prescribing decisions for each patient.

Patients were given a symptom diary. They were asked to rate 13 symptoms each day until recovery (or for 28 days if symptoms were on going) on a seven-point scale comprising the following responses: "normal/not affected", "very little problem", "slight problem", "moderately bad", "bad", "very bad" and "as bad as it can be". This approach to outcome measurement has been used in other studies of acute cough/ LRTI and has been found to be responsive to change and discrimination [18]. Patients rated the same symptoms as the clinicians except for confusion/disorientation and diarrhoea. They were, in addition, asked about interference with social activities. A patient-rated total symptom severity score was calculated by summing the scores for each symptom and scaling it so that it could be interpreted as a percentage symptom severity score.

The CRF and patient diary were translated into local languages and then back-translated into English for accuracy checks by the central study team. Final face-to-face validity checks were made with practicing bilingual clinicians.

\section{Analysis}

We used a two-level (patients nested within clinicians) logistic regression with antibiotic prescription as the outcome to investigate whether patients with discoloured sputum (yellow, green or yellow/green) or normal sputum were more likely to be prescribed antibiotics than those producing no sputum, and whether patients feeling generally unwell (comprising those who reported feeling mildly, moderately or severely unwell) were more likely to be prescribed antibiotics than those not feeling generally unwell.

A three-level (daily symptom scores nested within patients nested within clinicians) hierarchical ARMA (autoregressive part and a moving average) $(1,1)$ model [19] was fitted to the log scale (to improve model fit) daily symptom scores to investigate whether patient subgroups had significantly different symptom severity at baseline and symptom score resolution over time. An ARMA $(1,1)$ model expresses each observation as a combination of the two:

$X t=\varepsilon t+X t-1+\varepsilon t-1$

where $X t$ is the symptom severity score at time $t, \varepsilon t$ is the error term. This allows for each individual's symptom severity scores and the related error term to be correlated with the previous day. The subgroups were those: reporting yellow sputum; reporting green sputum; who felt mildly unwell; who felt moderately unwell; who felt severely unwell; and who had discoloured sputum (yellow or green) and felt generally unwell. The reference category for these analyses was those not producing sputum and who did not report feeling generally unwell. Interaction terms were fitted for each of these subgroups to investigate whether being prescribed an antibiotic was associated with a difference in symptom 
resolution. This was investigated using a three-way interaction term between belonging to one of these subgroups, being prescribed an antibiotic and time measured in days.

These analyses controlled for clinical presentation by including patient information on 12 out of the 14 clinician-recorded symptoms (cough was excluded as it was present in $99.8 \%$ of cases and feeling generally unwell is one of the symptoms of interest), temperature, age, comorbidities (cardiovascular, respiratory including COPD, COPD alone, diabetes and asthma), the number of days waited before presentation, smoking status and network. We did not sum clinician ratings of symptoms into a scale. Comorbidities, including COPD and asthma, were ascertained by the treating clinician from their knowledge of the patient and the clinical record. Additional diagnostic tests were not performed for the purposes of this study. No imputation was performed on the patient-reported symptom scores.

In order to illustrate the differences in symptom resolution between subgroups and between those prescribed antibiotics or not within the subgroups, estimated patient-reported symptom scores on day 7 are presented for each of the subgroups, split by whether they were prescribed antibiotics or not. We performed sensitivity analyses to investigate differences in patient-reported symptom score resolution between those prescribed and those not prescribed antibiotics in three subgroups of patients with discoloured sputum who were also feeling generally unwell (i.e. those who also had COPD, those who also had asthma and those who were aged $>65 \mathrm{yrs}$ ).

\section{RESULTS}

A total of 3,402 patients were recruited by 387 practitioners. Six networks included $\geqslant 270$ patients, and all included $>100$. Four patients were later found to be ineligible and were therefore excluded from further analysis. CRFs were completed for 3,368 (99\%) and diary data was obtained from 2,714 (80\%) patients (fig. 1). Online supplementary table 1 shows the characteristics of included patients by network.

Patients who returned the diary data were generally older (median age 47 versus $36 \mathrm{yrs}$ ) and more frequently prescribed antibiotics (54 versus $46 \%$ ), but were otherwise similar (table 1).

We analysed data from 2,419 patients with both useable CRF and patient diary data. The following variables had some missing values: phlegm production $(n=75)$, shortness of breath $(n=4)$, wheeze $(n=6)$, coryza $(n=11)$, fever $(n=18)$, chest pain $(n=7)$, muscle aching $(n=11)$, headache $(n=8)$, disturbed sleep $(\mathrm{n}=18)$, feeling generally unwell $(\mathrm{n}=13)$, interference in normal activities $(n=13)$, confusion $(n=4)$, diarrhoea $(n=5)$, temperature $(n=20)$, smoking status $(n=3)$ and sputum colour $(n=57)$. Of these, $638(26.4 \%)$ were producing yellow sputum and 451 $(18.6 \%)$ were producing green sputum, 1,940 (80.2\%) were feeling generally unwell, and 897 (37.1\%) were producing yellow or green sputum and also feeling generally unwell. 137 $(5.7 \%)$ had COPD. Those who the clinician rated as feeling generally unwell (mild $n=734,30.3 \%$; moderate $n=947,39.1 \%$; severe $n=259,10.7 \%$ ) also had higher self-rated symptom severity scores for day 1 of the self-competed diary compared with those for whom the clinician recorded that feeling generally unwell was "not a problem". This suggests that

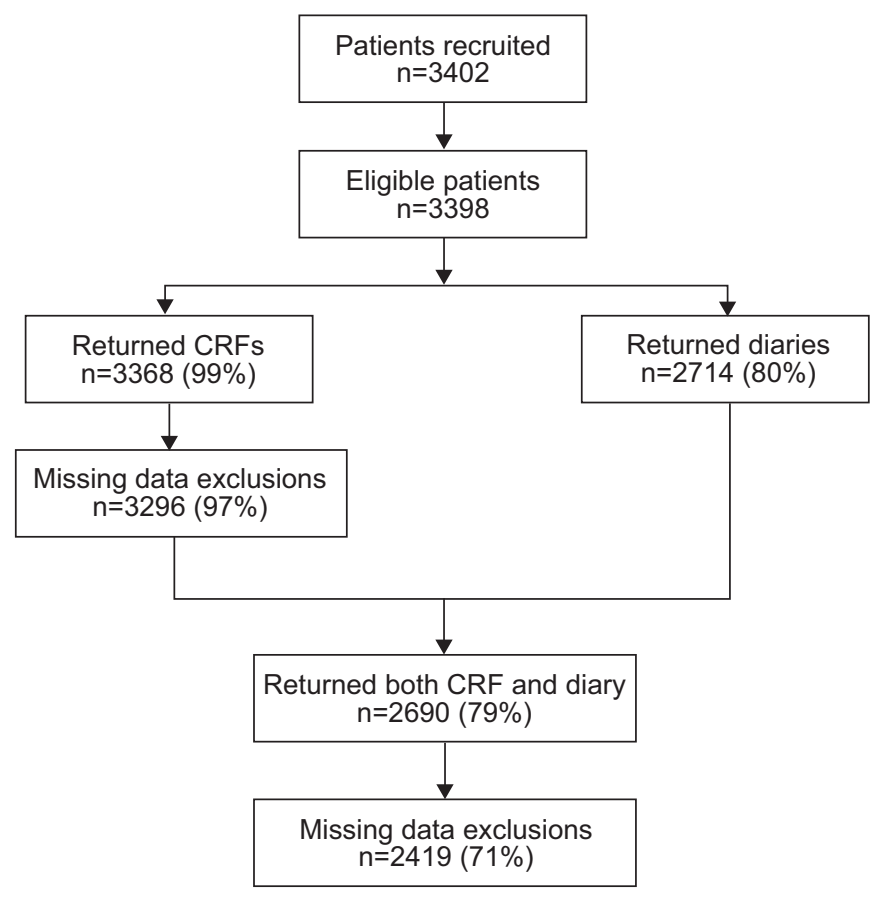

FIGURE 1. Patient flowchart. CRF: case report form

clinicians' ratings of illness severity was congruent with patients' own assessments of the severity of their symptoms.

Those producing normal sputum were not prescribed antibiotics more frequently than those not producing sputum (OR 0.95, 95\%

\begin{tabular}{|c|c|c|}
\hline \multirow[t]{2}{*}{ TABLE 1} & \multirow[b]{2}{*}{ Responders } & \multirow[b]{2}{*}{ Nonresponders } \\
\hline & & \\
\hline Males & $973(36)$ & 255 (38) \\
\hline Age yrs & $47(35-60)$ & $36(27-48)$ \\
\hline Temperature ${ }^{\circ} \mathrm{C}$ & $36.8(36.4-37.2)$ & $36.7(36.2-37.1)$ \\
\hline $\begin{array}{l}\text { Total clinician-recorded } \\
\text { symptom severity score }\end{array}$ & $26(22-31)$ & 27 (23-32) \\
\hline Antibiotic prescription & $1464(54)$ & $312(46)$ \\
\hline \multicolumn{3}{|l|}{ Comorbidity } \\
\hline Respiratory & $395(15)$ & 120 (18) \\
\hline Diabetes & $126(5)$ & $12(2)$ \\
\hline Cardiovascular & $240(9)$ & $26(4)$ \\
\hline Discoloured sputum & $1223(45)$ & $321(47)$ \\
\hline Yellow & $689(26)$ & $150(22)$ \\
\hline Green & $498(19)$ & $159(23)$ \\
\hline Blood-stained & $36(1)$ & $12(2)$ \\
\hline \multicolumn{3}{|l|}{ Feeling generally unwell } \\
\hline No problem & $557(21)$ & $151(22)$ \\
\hline Mild problem & $803(30)$ & $146(22)$ \\
\hline Moderate problem & $1036(39)$ & $273(40)$ \\
\hline Severe problem & $281(10)$ & $90(13)$ \\
\hline Patients & 2690 & 678 \\
\hline
\end{tabular}

Data are presented as $n, n$ (\%) or median (interquartile range) 
CI 0.61-1.48). Those with discoloured sputum were more likely to be prescribed antibiotics compared with those not producing sputum (OR 3.2, 95\% CI 2.1-5.0). Those feeling generally unwell (any category) were not prescribed antibiotics any differently than those not feeling generally unwell (overall $\mathrm{p}=0.24$ ).

Online supplementary table 2 shows the symptom severity at baseline and symptom resolution over time for the various subgroups and whether this was associated with antibiotic treatment for both adjusted (adjusted for clinician-recorded symptoms, temperature, age, comorbidities, number of days waited before presentation and smoking status) and unadjusted models. The three subgroups of feeling generally unwell (mild, moderate or severe) were observed to have higher symptom severity at baseline and to recover slightly faster than those who were recorded as not feeling generally unwell. However, within these subgroups those treated with antibiotics were no different in terms of symptom severity or resolution compared to those not treated with antibiotics (supplementary table 2).

Sputum colour (yellow or green) was not associated with symptom severity at baseline or with resolution over time in the adjusted models. Moreover, producing discoloured sputum while also feeling generally unwell was not associated with symptom severity at baseline or resolution over time. All of this information is presented in the supplementary material.

Table 2 provides estimates of the differences in \% symptom severity scores based on the coefficients presented in the supplementary material. These differences in symptom resolution were small (table 2), with the estimated symptom severity scores on day 7 ranging between $3.9 \%$ (green sputum group) and $5.1 \%$ (yellow / green and feeling severely unwell group) for those who were not prescribed antibiotics, and between $3.9 \%$ (yellow/green sputum and feeling mildly generally unwell) and 5\% (yellow/green and feeling severely unwell group) for those who were. The differences between those who were and were not prescribed antibiotics were not statistically significant. The estimated symptom resolution for each subgroup is illustrated in figure 2.

Antibiotics were prescribed for $67.4 \%(n=124)$ of patients with COPD, $57.9 \%(n=195)$ of patients with asthma, and $54.5 \%$
( $n=265)$ of patients aged $>65$ yrs. In these subgroups of patients, symptom resolution for patients with discoloured sputum who were also feeling generally unwell was not associated with antibiotic treatment (final three entries in supplementary table 2).

\section{DISCUSSION}

\section{Summary of main results}

This is the only large prospective study in a primary care setting to examine the relationship between sputum colour and/or feeling generally unwell and symptom resolution, and whether or not this was associated with antibiotic treatment. We found that adults presenting in primary care with an acute cough and who produced discoloured sputum were more likely to be prescribed antibiotics. However, we also found no clinically meaningful associations between sputum colour and/or feeling generally unwell with symptom resolution. Furthermore, symptom resolution was not associated with antibiotic treatment in patients with discoloured sputum who were also feeling generally unwell and those who belonged to both of these subgroups. The biggest difference between those who were and were not treated with antibiotics was less than one half of a percentage point on a symptom severity scale (table 2).

We have previously considered the relationship between antibiotic prescription in general and prescribing by antibiotic class with outcomes for all patients, and found no clinically meaningful association with patients' outcomes in this group $[3,20]$.

\section{Strengths and weaknesses}

An advantage of this observational study design is that treatment decisions were left up to the treating clinician, unlike in a randomised study, making our results more applicable to actual practice. Not requiring additional nonroutine investigations also makes this study more applicable to everyday practice. Randomising patients with discoloured sputum to either receive or not receive antibiotic treatment could increase internal validity, but some patients might not wish to participate if they risk being randomised to a particular treatment or to placebo when they feel particularly unwell. Furthermore, there is some evidence that older patients may derive benefit from antibiotic treatment [21].

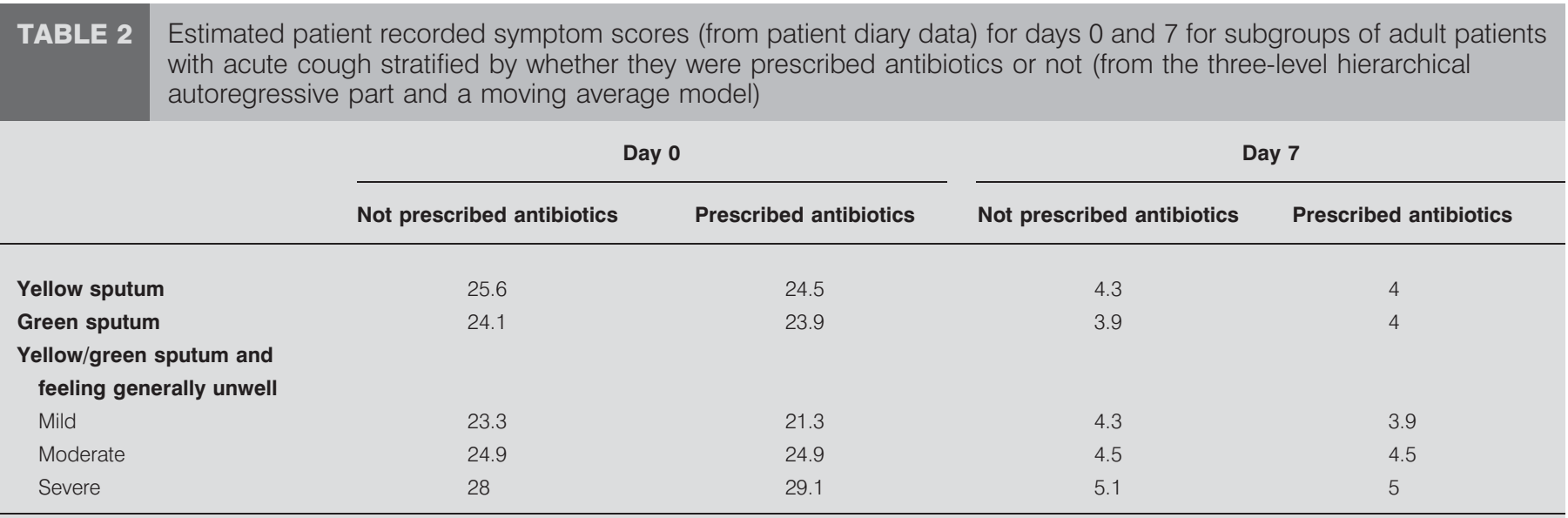

Data are presented as symptom scores. 


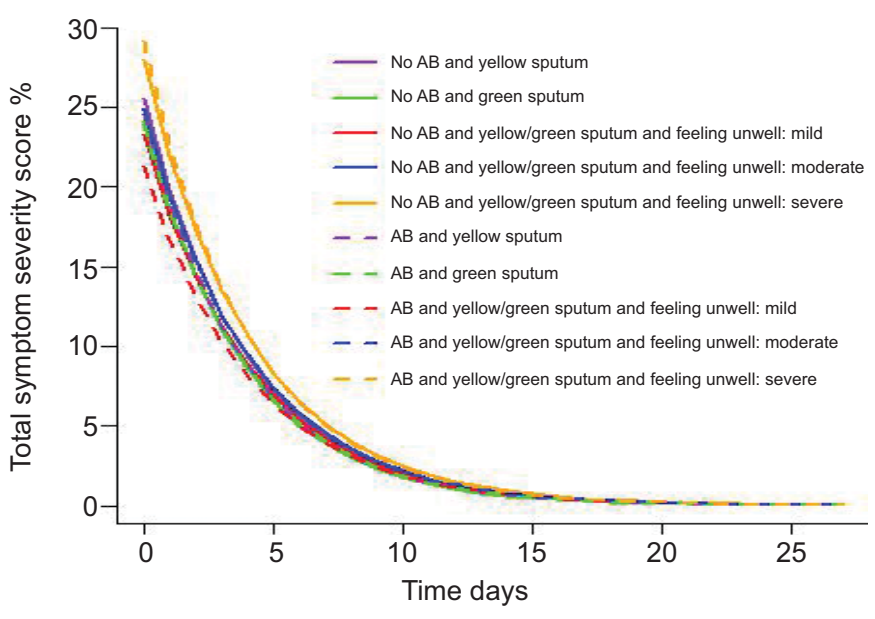

FIGURE 2. Estimated patient-recorded scaled symptom severity scores over 28 days after presentation for the subgroups of adult patients with acute cough from the three-level hierarchical autoregressive part and a moving average model. $\mathrm{AB}$ : antibiotic.

We did not attempt to infer causality from these data. Our analyses were designed to identify associations.

We included a large number of patients from a variety of primary care settings across Europe with close to complete ascertainment of baseline characteristics by clinicians and with an $80 \%$ return rate of patients' self-completed follow-up symptom diary data. We were able to control for several known possible confounders (illness severity at the time of the index consultation, standardised measurement of body temperature, patient age, number of days ill before the index consultation, diabetes, cardiovascular or respiratory (including COPD and asthma) comorbidities and smoking status). A wide range of physician-assessed symptoms and signs were individually included in our models. However, this observational design could not account for unknown confounders. The patients in this study represent the larger, but milder, end of the clinical spectrum of patients with acute cough, and the findings cannot be uncritically applied to patients with more severe lung disease, who, for example, may have well-defined acute exacerbations of COPD. However, our sensitivity analysis for the patients with COPD, those with asthma and those aged $>60$ yrs showed sputum colour while feeling generally unwell was not associated with benefit from antibiotic treatment. Therefore, in these subgroups of patients antibiotic treatment was not associated with greater rate or magnitude of symptoms resolution, even in those with discoloured sputum and who were feeling generally unwell (final three entries in supplementary table 2). We did not record data on sputum consistency. Sputum colour was determined, as is common in routine practice, by asking the patient rather than confirming colour using charts, which adds to applicability of findings to everyday primary care. We did not monitor change in sputum colour over time, as our goal was to explore the prognostic usefulness of sputum colour at the time of presentation. The clinicians who recruited patients also recorded data on them. Ideally, severity assessment would have been separated from management decisions, but it was not possible to have researchers at each participating practice, which is usually the case with most primary care research of this nature. However, patient outcome was not assessed by recruiting clinicians and, as this was not a randomised study, ascertainment bias is unlikely. Clinicians did not keep a log of all eligible patients, those approached and the outcome as this was considered too burdensome in a pragmatic study. We only considered antibiotic treatment at the initial consultation in our analyses. As our main study questions related to associations between symptoms, antibiotic prescription and outcomes, patient adherence to antibiotic prescriptions were not considered in the analysis.

\section{Comparison with existing literature}

We found that patients presenting with acute cough in primary care who have discoloured sputum are more likely to be prescribed antibiotics than those not producing sputum or producing white sputum. This confirms previous findings that physicians are more likely to prescribe antibiotics to patients with presumed respiratory tract infections (RTIs) who produce purulent sputum. CoENEN et al. [22] analysed data from 72 Flemish general practitioners (GPs) on the management of 1,448 patients with acute cough. The presence of sputum was associated with an increased risk of antibiotic prescription independent of patient and clinician characteristics (OR 2.5, 95\% CI 1.62-3.92). FISCHER et al. [10] directly observed 30 GPs in Germany managing 237 patients with RTIs. Purulent sputum was associated with an increased chance of antibiotic prescription (OR 2.1, 95\% CI 1.1-4.1). In another study from Germany, HuMMERS-PRADIER et al. [7] found increased antibiotic prescription for RTIs when patients had yellow or green sputum (OR 4.4, 95\% CI 1.84-10.69). In the Netherlands, discoloured sputum was related to antibiotic treatment and was one of the reasons for overprescribing in LRTI [23]. In the USA, GONZALES et al. [24] found antibiotic prescription for upper RTI was increased when patients produced green sputum (OR 4.8, 95\% CI 2.4-11.1) and DosH et al. [25] found antibiotic prescription increased in association with smokers coughing up green or yellow sputum (OR 2.5, 95\% CI 1.7-3.8). AlTINER et al. [26] obtained sputum samples from 241 patients with acute cough in primary care and found 136 of these were coloured yellow or greenish. Only 28 samples yielded pathogens on culture. The sensitivity of yellowish or greenish sputum as a test for bacterial infection was 0.79 (95\% CI 0.63-0.94) and the specificity 0.46 (95\% CI 0.038-0.53).

We know from a trial in volunteers that antibiotic-resistant oral streptococci persist for $\geqslant 180$ days as a consequence of antibiotic exposure [27]. In that study, follow-up was for $\leqslant 28$ days, so was unable to capture either possible harm from resistance or benefits from reducing bacterial colonisation and possible subsequent inflammation.

None of these studies explored the relationships between sputum colour and outcomes. We were not able to identify any previous large prospective studies examining the associations between sputum colour or feeling generally unwell and outcome, and whether or not this was associated with antibiotic treatment.

Previous trials have, however, showed no meaningful benefit from antibiotic treatment, on average, for patients consulting in primary care with acute cough and purulent sputum [18, 21, 28, 29]. 
The European Respiratory Society guidelines for the management of adult LTRIs recommend that for patients managed outside hospital, antibiotics should be considered only for those with suspected or definite pneumonia, selected exacerbations of COPD and in patients with acute bronchitis, and with age $>75$ yrs and fever, and/or cardiac failure, insulin dependent diabetes and serious neurological disorders [30]. The US Centers for Disease Control and Prevention Physician Information Sheet on Acute Cough Illness (Acute Bronchitis) recommends against empiric antibiotic treatment [31]. They cite evidence that $>95 \%$ of patients with purulent sputum do not have symptoms of pneumonia [32].

\section{Implications for policy and practice}

This study focused on a broad category of adult patients, namely those with acute cough consulting in a broad range of general medical practice settings in Europe. The findings suggest that physicians should not rely on sputum colour, either on its own or in conjunction with patients feeling generally unwell, when deciding whether or not to prescribe an antibiotic for such patients. These data will have relevance to a large number of health care encounters. Acute cough is the largest single acute cause of consultation in primary care in the UK [1]. In the USA, there were about 10 million office visits for acute bronchitis in 1997 [33]. Implementing this evidence is likely to reduce antibiotic prescription for those with acute cough who are unlikely to benefit from antibiotic treatment and, thus, contribute to containing antibiotic resistance [26].

\section{SUPPORT STATEMENT}

This study was funded by 6th Framework Programme of the European Commission (LSHM-CT-2005-518226). The South East Wales Trials Unit is funded by the Wales Office for Research and Development. The funders had no role in the design and conduct of the study, or the collection, management, analysis or interpretation of the data, or in the preparation, review or approval of this manuscript. C.C. Butler had full access to all the data in the study and takes responsibility for the integrity of the data and the accuracy of the data analysis. He is the guarantor. A. Torres was supported by grant 2009 SGR 911 from Ciber de Enfermedades Respiratorias (Ciberes CB06/06/0028); the Ciberes is an initiative of the Instituto de Salud Carlos III.

\section{CLINICAL TRIAL}

This study is registered at ClinicalTrials.gov with identifier number NCT00353951.

\section{STATEMENT OF INTEREST}

Statements of interest for T. Schaberg, T. Verheij and A. Torres can be found at www.erj.ersjournals.com/site/misc/statements.xhtml

\section{ACKNOWLEDGEMENTS}

The authors' affiliations are: C.C. Butler, Dept of Primary Care and Public Health, School of Medicine, Cardiff University, Cardiff, UK; M.J. Kelly, Dept of Primary Care and Public Health, School of Medicine, Cardiff University, Cardiff, UK; K. Hood, Dept of Primary Care and Public Health, School of Medicine, Cardiff University, Cardiff, UK; T. Schaberg, Center of Pneumology, Deaconess Hospital Rotenburg, Rotenburg, Germany; H. Melbye, General Practice Research Unit, Institute of Community Medicine, University of Tromsø, Tromsø, Norway; M. Serra-Prat, Unitat de Recerca, Hospital de Mataró, Mataro, Spain; F. Blasi, Respiratory Medicine Section, Dipartimento ToracoPolmonare e Cardiocircolatorio, University of Milan, IRCCS Fondazione Ca' Granda, Milan, Italy; P. Little, School of Medicine, University of Southampton, Southampton, UK; T. Verheij, Julius
Center for Health, Sciences and Primary Care, University Medical Center Utrecht, Utrecht, the Netherlands; S. Mölstad, Dept of Medical and Health Sciences, Linköping University, Linköping, Sweden; M. Godycki-Cwirko, Dept of Family and Community Medicine, Medical University of Łódź, Lodz, Poland; P. Edwards, Ely Bridge Surgery, Cardiff, UK; J. Almirall, Unitat de Cures Intensives, Hospital de Mataró, Mataro, Spain; A. Torres, Pneumology Dept, Clinic Institute of Thorax, Hospital Clinic of Barcelona, Insitut d'Investigacions Biomèdiques August Pi i Sunyer, University of Barcelona, Ciber de Enfermedades Respiratorias, Barcelona, Spain; U-M. Rautakorpi, Finnish Office for Health Technology Assessment Finohta, National Institute for Health and Welfare THL, Tampere, Finland; J. Nuttall, Dept of Primary Care and Public Health, School of Medicine, Cardiff University, Cardiff, UK; H. Goossens, Laboratory of Medical Microbiology, Vaccine and Infectious Disease Institute, University of Antwerp, Antwerp, Belgium; and S. Coenen, Laboratory of Medical Microbiology, Vaccine and Infectious Disease Institute, University of Antwerp, Antwerp, Belgium.

We acknowledge the entire GRACE team for their diligence, expertise and enthusiasm. The GRACE team are: Z. Arvai (DRC Ltd, Balatonfured, Hungary), Z. Bielicka (Clinical Research Associates and Consultants, Bratislava, Slovakia), A. Borras (CAPSE, Barcelona, Spain), C. Brugman (University Medical Center Utrecht Julius Center for Health Sciences and Primary Care, Utrecht, the Netherlands), J. Coast (University of Birmingham, Birmingham, UK), M. Davies (Ely Bridge Surgery, Cardiff, UK), K. Dirven (University of AntwerpCampus Drie Eiken, Antwerp, Belgium), I. Hering (Zentrum für Pneumologie Diakoniekrankenhaus, Rotenburg, Germany), J. Holczerné (DRC Ltd, Balatonfured, Hungary), K.A. Jakobsen (University of Tromsø, Tromsø, Norway), B. Kovacs (DRC Ltd, Balatonfured, Hungary), C. Lannering (University of Linköping, Jönköping, Sweden), F. Leus (University Medical Center Utrecht Julius Center for Health Sciences and Primary Care, Utrecht, The Netherlands), K. Loens (University of Antwerp, Antwerp, Belgium), M. Moore (WreN, Southampton, UK), M.Muras (Medical University of Lodz, Lodz, Poland), C. Pascoe (University of Tromsø, Tromsø, Norway), R. Smith (University of Birmingham, Birmingham, UK), J. Swain (Cardiff University, Cardiff, UK), P. Tarsia (University of Milan, Milan, Italy), K. Valve (Stakes/Finohta, Tampere, Finland), R.Veen (University Medical Centre Utrecht, Utrecht, the Netherlands) and T. Worby (Aldermoor Health Centre, Southampton, UK). We thank all the clinicians and patients who consented to be part of GRACE, without whom this study would not have been possible.

\section{REFERENCES}

1 Ashworth M, Charlton J, Ballard K, et al. Variations in antibiotic prescribing and consultation rates for acute respiratory infection in UK general practices 1995-2000. Br J Gen Pract 2005; 55: 603-608.

2 Mainous AG, Hueston WJ, Davis WP, et al. Trends in antimicrobial prescribing for bronchitis and upper respiratory infections among adults and children. Am J Public Health 2003; 93: 1910-1914.

3 Butler CC, Hood K, Verheij T, et al. Variation in antibiotic prescribing and its impact on recovery in patients with acute cough in primary care: prospective study in 13 countries. BMJ 2009; 338: b2242.

4 Butler CC, Dunstan F, Heginbothom M, et al. Containing antibiotic resistance: decreased antibiotic-resistant coliform urinary tract infections with reduction in antibiotic prescribing by general practices. Br J Gen Pract 2007; 57: 785-792.

5 Cosby JL, Francis N, Butler CC. The role of evidence in the decline of antibiotic use for common respiratory infections in primary care. Lancet Infect Dis 2007; 7: 749-756.

6 Gonzales R. A 65-year-old woman with acute cough illness and an important engagement. JAMA 2003; 289: 2701-2708. 
7 Hummers-Pradier E, Pelz J, Himmel W, et al. Treatment of respiratory tract infections: a study in 18 general practices in Germany. Eur J Gen Pract 1999; 5: 15-20.

8 Storring RA. Antibiotics for coughs and colds. Hello, virus. BM] 2008; 337: a1144.

9 Coenen S, Michiels B, Van Royen P, et al. Antibiotics for coughing in general practice: a questionnaire study to quantify and condense the reasons for prescribing. BMC Fam Pract 2002; 3: 16.

10 Fischer T, Fischer S, Kochen MM, et al. Influence of patient symptoms and physical findings on general practitioners' treatment of respiratory tract infections: a direct observation study. BMC Fam Pract 2005; 6: 6.

11 Wigton RS, Darr CA, Corbett KK, et al. How do community practitioners decide whether to prescribe antibiotics for acute respiratory tract infections? J Gen Intern Med 2008; 23: 1615-1620.

12 Morice AH, McGarvey L, Pavord I, et al. Recommendations for the management of cough in adults. Thorax 2006; 61: I1-I24.

13 Cals JW, Boumans D, Lardinois RJ, et al. Public beliefs on antibiotics and respiratory tract infections: an internet-based questionnaire study. Br J Gen Pract 2007; 57: 942-947.

14 Mainous AG, Zoorob RJ, Oler MJ, et al. Patient knowledge of upper respiratory infections: implications for antibiotic expectations and unnecessary utilization. J Fam Practice 1997; 45: 75-83.

15 Gonzales R, Bartlett JG, Besser RE, et al. Principles of appropriate antibiotic use for treatment of uncomplicated acute bronchitis: background. Ann Intern Med 2001; 134: 521-529.

16 Metlay JP, Kapoor WN, Fine MJ. Does this patient have community-acquired pneumonia? Diagnosing pneumonia by history and physical examination. JAMA 1997; 278: 1440-1445.

17 McIsaac WJ, Butler CC. Does clinical error contribute to unnecessary antibiotic use? Med Decis Making 2000; 20: 33-38.

18 Little P, Rumsby K, Kelly J, et al. Information leaflet and antibiotic prescribing strategies for acute lower respiratory tract infection - a randomized controlled trial. JAMA 2005; 293: 3029-3035.

19 Box G, Jenkins G. Time Series Analysis: Forecasting and Control. San Francisco, Holden-Day, 1976.

20 Butler CC, Hood K, Kelly MJ, et al. Treatment of acute cough/ lower respiratory tract infection by antibiotic class and associated outcomes: a 13 European country observational study in primary care. J Antimicrob Chemoth 2010; 65: 2472-2478.
21 Verheij TJM, Hermans J, Mulder JD. Effects of doxycycline in patients with acute cough and purulent sputum - a double-blind placebo-controlled trial. Br J Gen Pract 1994; 44: 400-404.

22 Coenen S, Michiels B, Renard D, et al. Antibiotic prescribing for acute cough: the effect of perceived patient demand. Brit J Gen Pract 2006; 56: 183-190.

23 Akkerman AE, Kuyvenhoven MM, van der Wouden JC, et al. Determinants of antibiotic overprescribing in respiratory tract infections in general practice. J Antimicrob Chemoth 2005; 56: 930-936.

24 Gonzales R, Barrett PH, Steiner JF. The relation between purulent manifestations and antibiotic treatment of upper respiratory tract infections. J Gen Intern Med 1999; 14: 151-156.

25 Dosh SA, Hickner JM, Mainous AG, et al. Predictors of antibiotic prescribing for nonspecific upper respiratory infections, acute bronchitis, and acute sinusitis - an UPRNet study. J Fam Practice 2000; 49: 407-414.

26 Altiner A, Wilm S, Daubener W, et al. Sputum colour for diagnosis of a bacterial infection in patients with acute cough. Scand J Prim Health 2009; 27: 70-73.

27 Amphora-Kumar S, Lammens C, Coenen S, et al. Effect of azithromycin and clarithromycin therapy on pharyngeal carriage of macrolide-resistant streptococci in healthy volunteers: a randomised, double-blind, placebo-controlled study. Lancet 2007; 10: 482-490.

28 Evans AT, Husain S, Durairaj L, et al. Azithromycin for acute bronchitis: a randomised, double-blind, controlled trial. Lancet 2002; 359: 1648-1654.

29 Stott NC, West RR. Randomised controlled trial of antibiotics in patients with cough and purulent sputum. BMJ 1976; 2: 556-559.

30 Woodhead M, Blasi F, Ewig S, et al. Guidelines for the management of adult lower respiratory tract infections. Eur Respir J 2005; 26: $1138-1180$.

31 US Centers for Disease Control and Prevention. Physician Information Sheet on Acute Cough Illness (Acute Bronchitis) www.cdc.gov/getsmart/campaign-materials/info-sheets/adultacute-cough-illness.html Date last accessed: May 6, 2011. Date last updated: June 30, 2009.

32 Diehr P, Wood RW, Bushyhead J, et al. Prediction of pneumonia in outpatients with acute cough: a statistical approach. J Chronic Dis 1984; 37: 215-225.

33 Schappert SM. Ambulatory care visits of physician offices, hospital outpatient departments, and emergency departments: United States, 1995. Vital Health Stat 1997; 13: 1-38. 